\section{The fiscal management of foreign aid in sub-Saharan Africa}

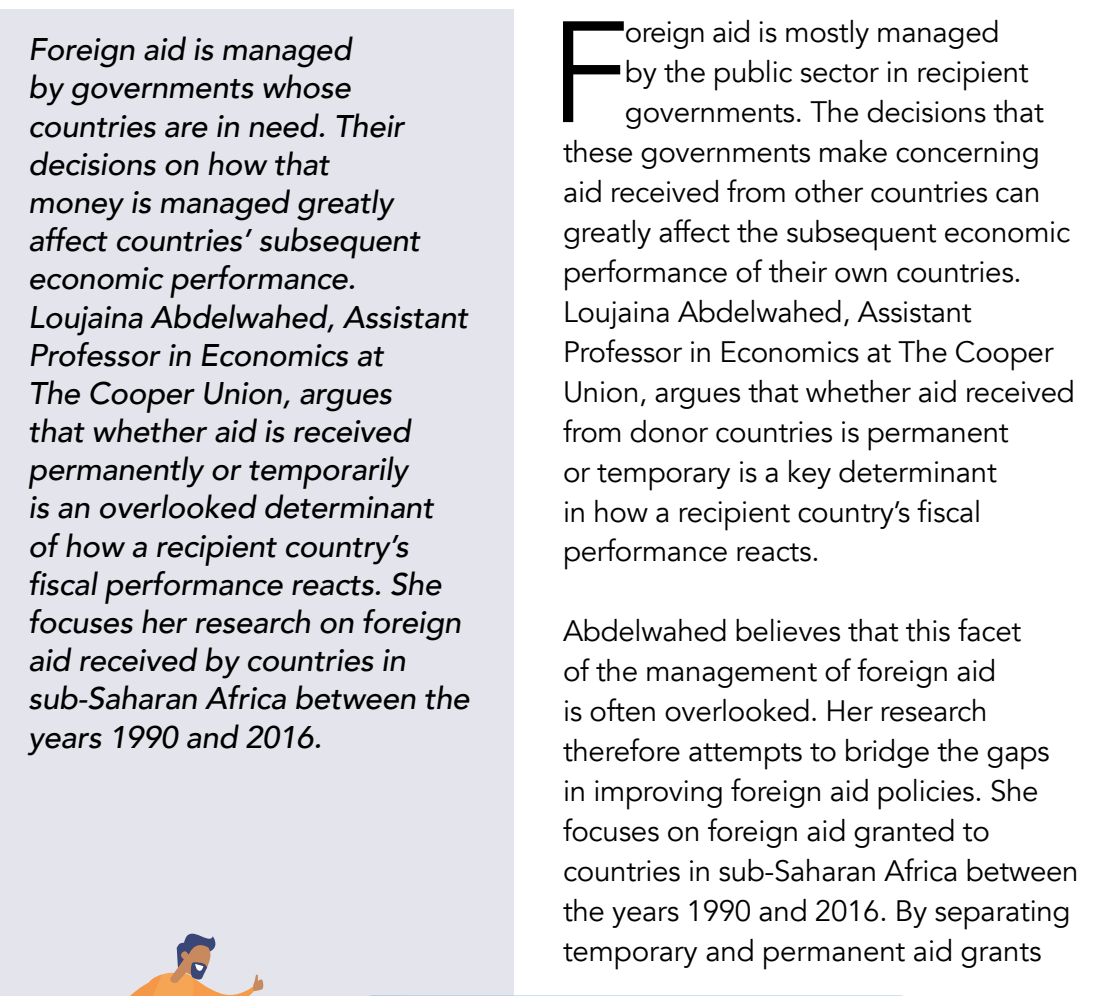

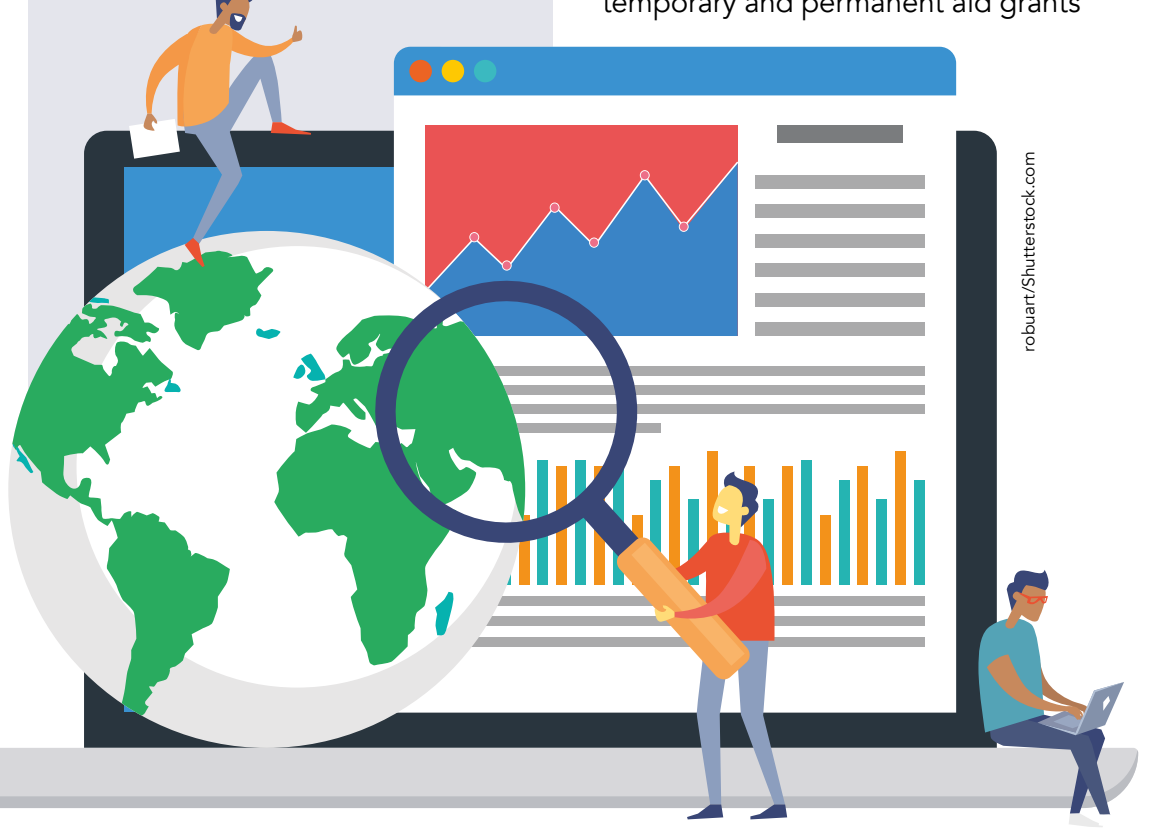

uring this time, Abdelwahed shows that the fiscal responses generated by the two distinct types of aid are meaningfully different. She goes on to provide important policy implications during the designing of aid programmes

Most of the research on foreign aid has focused on how governments large amounts of aid received. These studies highlight that aid is largely used to finance government spending on both consumption and investment, and that there are no robust effects on taxation policy. Other studies have attempted to differentiate between specific types of aid. For instance, one study found that project aid (which is directed to specific projects in specific sectors) increased public investment. In contrast, programme governments) leads to higher rates of government consumption.

An overlooked determinant of fiscal responses in prior studies, however, is whether aid monies received Overlooking this facet of foreign aid results in misleading estimates of the governmental fiscal responses. In her research, Abdelwahed separates the fiscal effects of temporary and permanent foreign aid, and assesses how each affects both recipient governments' financing choices (choice and their responses in term tisuance), and their responses in terms of recur spending, public investment, tax
collection, and domestic borrowing.

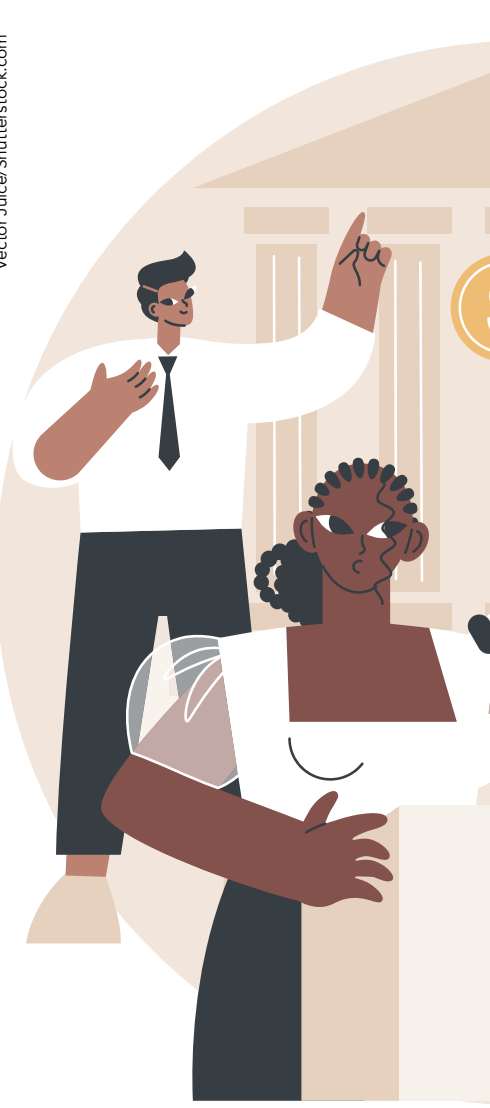

This allows for a relaxation of the
restriction imposed by most of the prior literature that insists that both temporary and permanent foreign aid have the same fiscal effects.

THE CHOICE BETWEEN

TAXATION AND DEBT ISSUANCE Abdelwahed argues that because foreign aid is considered an addition source of financing government operations, itulimately affects the concerning other sources of funding: namely, taxation and debt issuance.

Abdelwahed's methodology is comprised of a theoretical framework that shows that the impact of foreign aid on the aforementioned financing choices depends on whether aid

By testing the predictions of the theoretical framework on data from 26 sub-Saharan African countries over the period 1990-2016, the research shows that foreign aid received on a permanent basis is mostly associate with an increase in debt issuance (increasing the fiscal deficit). As
Abdelwahed explains, 'debt issuance commonly leads to a decrease in fiscal deficit. What is revealed most clearly the fiscal deficit to aid inflows is directly linked to the response of govermment spending. A permanent aid 'shock' leads to increasing the government spending by more than the amount of aid received, which leads to an increase in the fiscal. deficit. Yet a temporary aid shock tends to increase the government spending by less than the aid received, thus leaving funds to reduce the existing deficit.

\section{FISCAL RESPONSES}

TO FOREIGN AID

Abdelwahed also assesses the response of the government fisca operations to

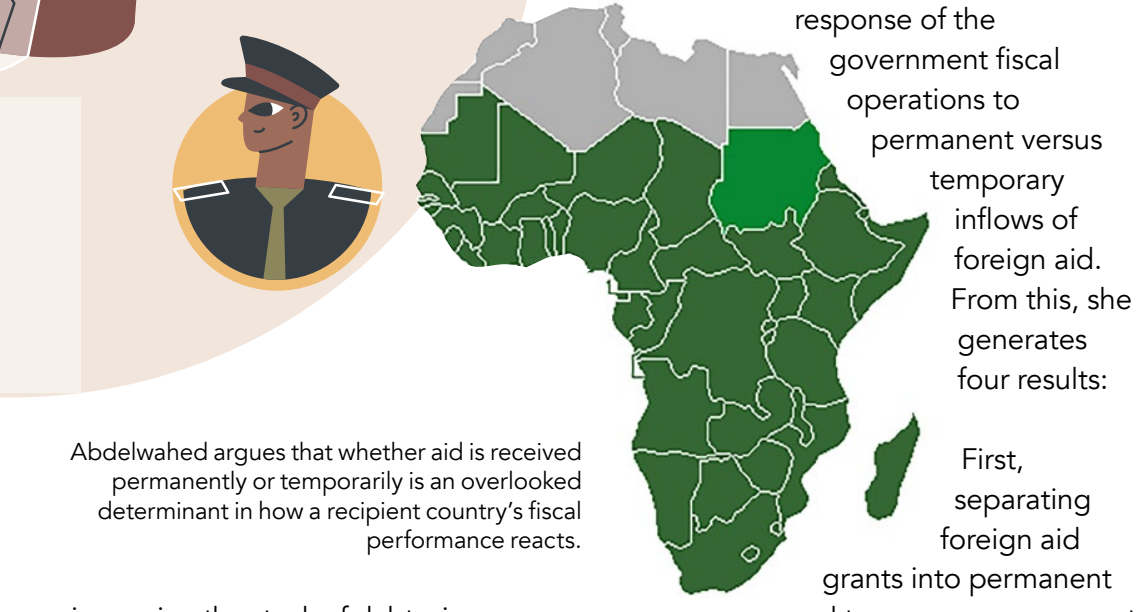

-increasing the stock of debt - is equivalent to increasing the fiscal deficti'. In contrast, foreign aid of the same size eads to different fiscal responses. Thus, failing to acknowledge these

Temporary aid may be more useful in supporting fiscal adjustment programmes in aid recipient countries in need of financial assistance.

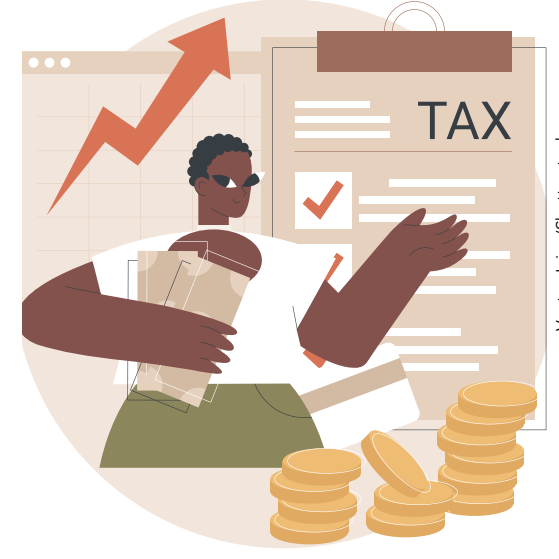

the estimated fiscal effects of a given recipient country's economy.

Second, temporary aid is associated with fiscal adjustments, such as increasing recurrent expenditure, while permanent aid is associated with higher public investments.

Third, even though foreign aid leads to a recipient government increasing its spending on both consumption and expenditure (ie, acquiring fixed aststs) Whether aid is received on a permanent or
temporary basis does not seem to impact
recipient government's 


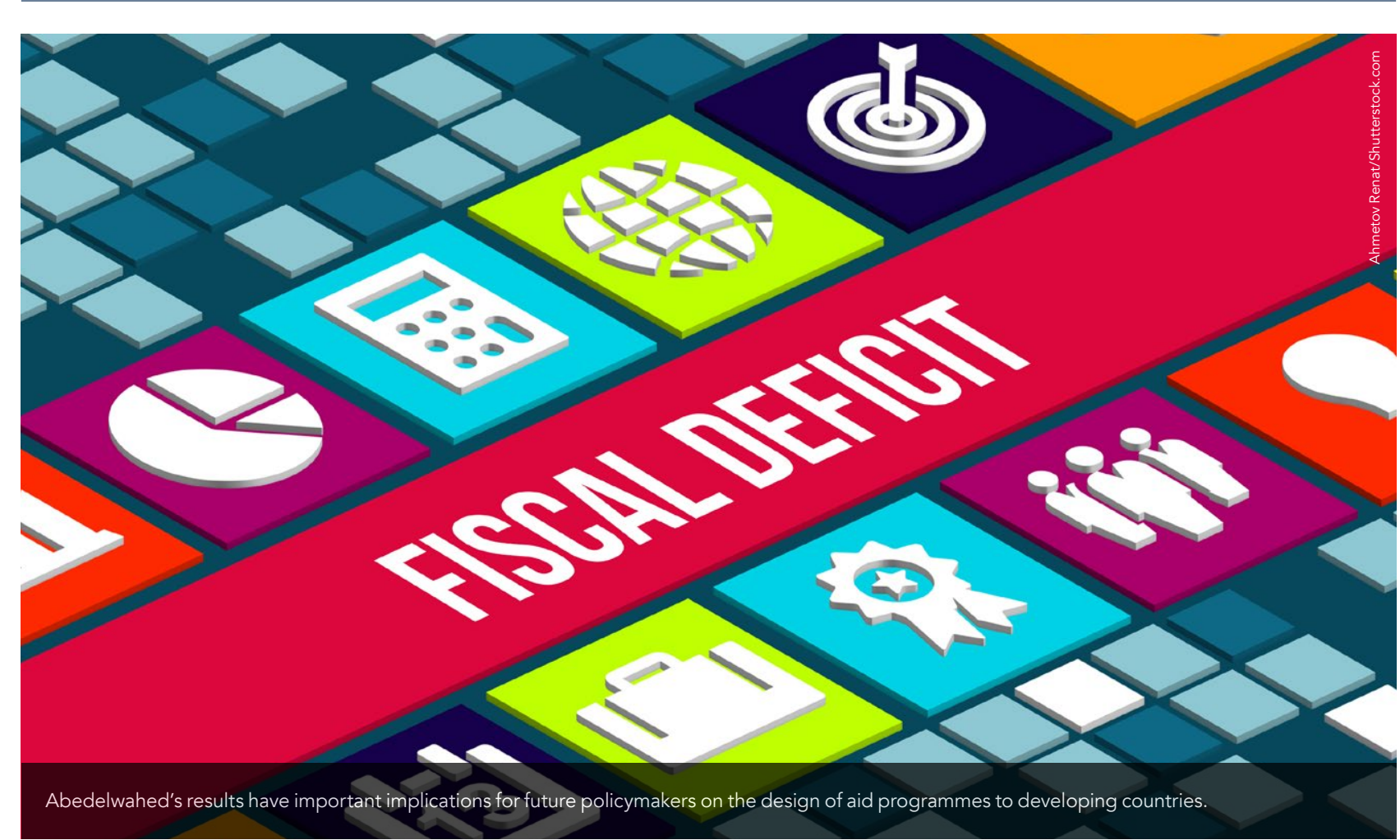

compared to the response of recurrent expenditure (ie, spending that does not result in acquiring fixed assets). building a hospital (ie, investment) then the recurrent expenditure will be the subsequent costs of running the hospital. So the increased recurrent expenditure is in fact, complementary to investment expenditure.

Furthermore, the response of public expenditure to permanent aid is larger to the response to ten rompared to this suggests that stabolising aid. can lead to less volatility in public investments and generate stronger economic growth.

estimating how a government chooses to respond to received foreign aid (ie,
grants versus loans versus debt relief) would be misleading, as the frequency of these types of aid would affect the recipient government's decision.

investments. This might be a chann for economic growth and the alleviation of poverty

This is compliant with existing Iterature which claims that a stabilised and consistent flow of received aid Understanding how foreign aid received helps developing countries with on either a temporary or permanent basis is allocated to specific budgetary uses will elucidate how that aid will Equally important is the fact that affect the economic performance of the temporary foreign aid helps to reduce recipient country.

Abedelwahed's results have further important implications for future programmes to developing aid First is the fact that stabilising foreigh a recipient country's fiscal deficit, whic makes it suitable and advantageous to countries seeking a fiscal adjustment fiscal adjustments, such as a reduction in domestic borrowing, and therefore may be more useful in improving fiscal circumstances in circumstances in
countries in need Fourth, whether Stabilising foreign aid flows, though $\begin{aligned} & \text { countries in need of } \\ & \text { aid is received on }\end{aligned}$ economic assistance.

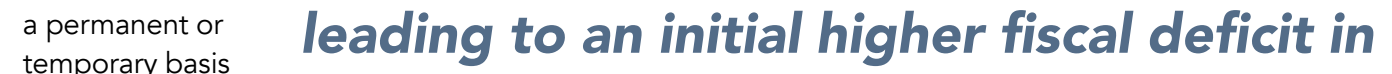
temporary basis soem to recipient countries, promotes an increase impact a recipien government's in public spending. tax-collection

policy. Temporary aid is associated with a slight, temporary increase in tax collection, while permanent aid is not associated with any changes.

Abdelwahed's findings have some important implications. Merely aid flows, although leading to higher fiscal deficit and borrowing in recipient countries, actually promotes an increase in public spending Although permanent aid leads to higher borrowing, it generates
However, in countries where public spending increases by more in response
to foreign aid than or axation, policymakers must develop taxation, policymakers must develop economic conditions and foreign aid programmes that ensure aid is an
effective means of development, rather effective means of development, rat than merely enabling
financial operations.
Research Objectives

Loujaina Abdelwahed's research focuses on foreign aid and natural resources and their impact on fiscal decisions and economic inequalities.

\section{Detail}

Bio

Loujaina Abdelwahed is Assistant Professor of Economic at the Faculty of Humanities and Social Sciences at The Cooper Union. She received her PhD in Economics from the University of llinois at Chicago. Prior to that, she worked as an ofonis the Egyptian Ministry of Finance.

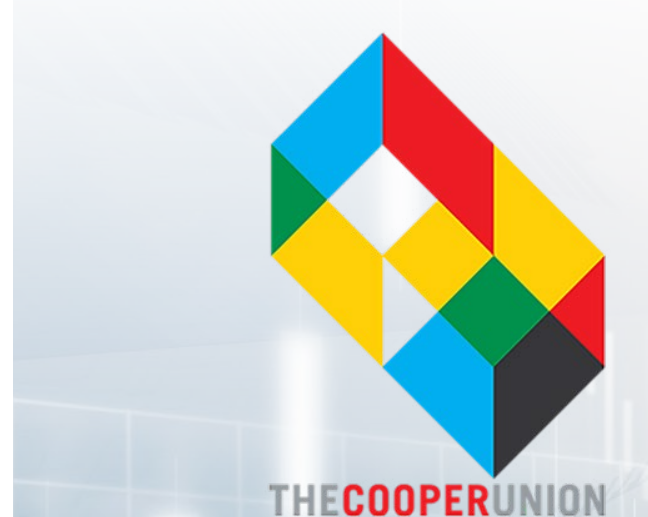

THECOOPERUNION

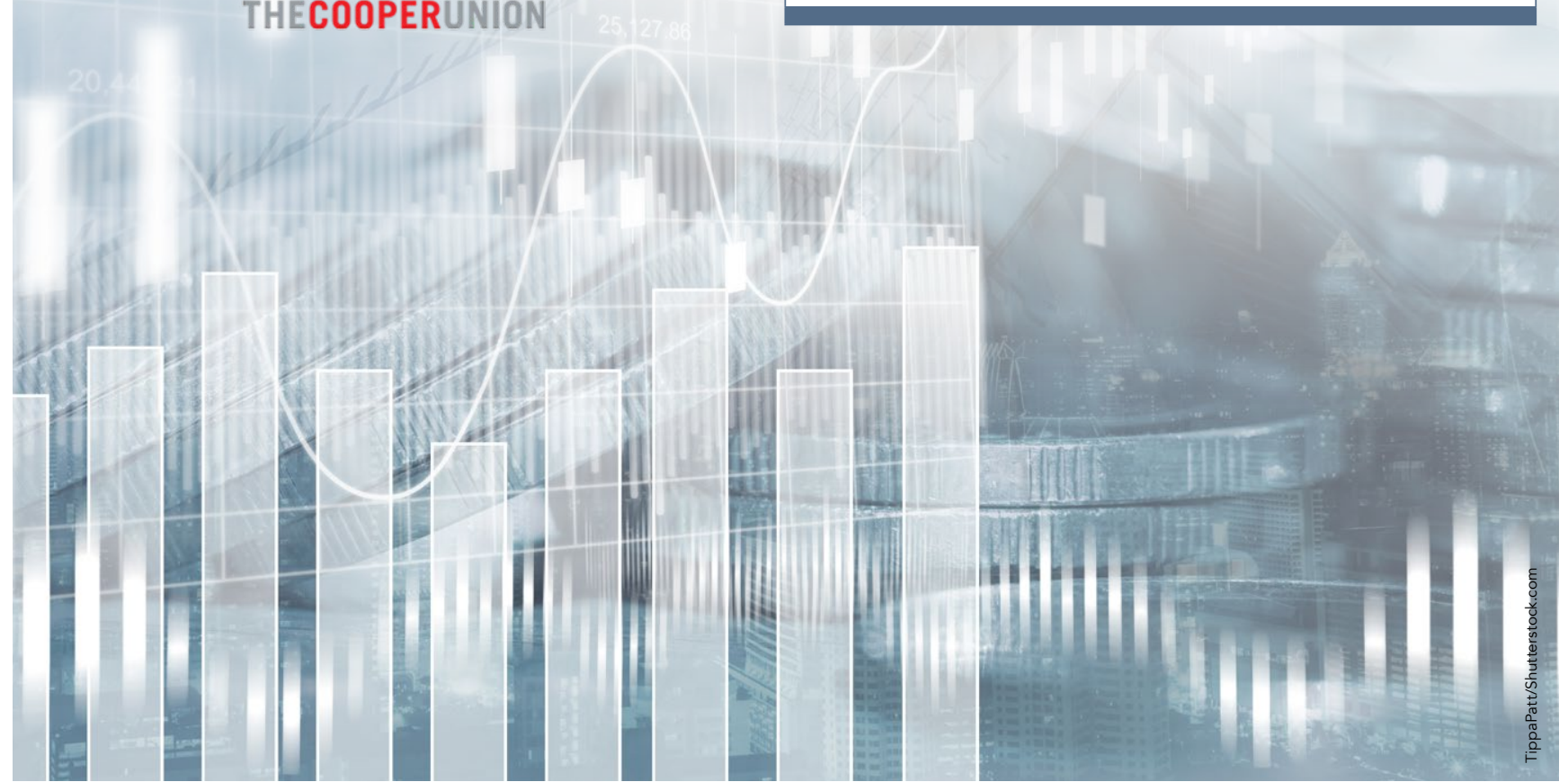

\section{References}

Abdelwahed, L, (2022) Fiscal Responses to Foreign Aid: Does the Permanence of Aid Matter? Journal of African Economies, ejac001. doi.org/10.1093/jae/ejac001

Abdelwahed, L, (2021) The fiscal management of permanent and temporary foreign aid. Journal of International

\section{Personal Response}

Could you provide us with a case study of where either permanent or temporary aid was a great success in II An example of temporary aid that can help countries improve their fiscal conditions are IMF-supported programmes. When countries borrow from the IMF, they agree to adjust their economic policies according to the targets on the government for a sub-Saharan African country that benefited from such a programme is Ghana, which in 2015 took a \$918 million loan to stabilise the economy. The budget deficit decreased from 13\% of GDP in 2014 to about 5\% of GDP in 2018. (source: www.imf.org/en/Countries/GHA/ghana-lending-
case-study). 